\title{
Medisinsk fødselsregister, en hjørnesten i norsk epidemiologi
}

\author{
Lorentz M. Irgens \\ Medisinsk fødselsregister, Universitetet $i$ Bergen \\ Armauer Hansens hus, Haukeland sykehus, 5021 Bergen \\ Telefon: 55974667 telefax: 55974998 e-mail: lorentz.irgens@mfr.uib.no
}

\begin{abstract}
SAMMENDRAG
Medisinsk fødselsregister (MFR) ble opprettet i 1967 etter thalidomidekatastrofen som førte til at mer enn 10.000 barn ble født med alvorlige reduksjonsdeformiteter. Formålet var spesielt å oppdage eventuelle nye hyppighetsøkninger av medfødte misdannelser så snart som mulig, og generelt å etablere et grunnlag for epidemiologiske studier av perinatale helseproblemer. Denne todeling i forvaltning og forskning har senere vært retningsgivende for MFR. Forvaltningen, den epidemiologiske overvåking av perinatale helseproblemer, har bidradd til å avklare en rekke alarmer i form av hyppighetsøkninger, og til å redusere usikkerhet knyttet til miljøproblemer og fosterskader. Den største utfordringen hittil har vært overvåkingen etter Tsjernobylkatastrofen. Et miljø som synes å innebære stadig større potensielle trusler, representerer en utfordrende arbeidsoppgave i fremtiden. Den andre viktige forvaltningsoppgaven knytter seg til tilsyn med og kvalitetssikring av helsetjenestene for gravide, fødende og nyfødte.

Den epidemiologiske forskningen er rettet mot årsakene til ulike perinatale helseproblemer og mot oppfølgning av ulike tilstander ved fødselen som for eksempel lav Apgar score eller forskjellige medfødte misdannelser. Longitudinelle studier der søskenflokken er analyseenhet i stedet for den enkelte fødsel står sentralt i forskningen. Slike studier har vist at den tilsynelatende veletablerte risikogruppen «høy paritet» er dårlig begrunnet både klinisk og forskningsmessig. Den høye risikoen observert i tverrsnittstudier skyldes heterogenitet ved at høyparitetsmødre i langt større utstrekning har mistet barn i tidligere svangerskap. Høyparitetsmødre uten tidligere tap har en meget lav risiko. Søskenflokkstudier av krybbedød har avdekket en langt lavere gjentakelsesrisiko enn dem som har vært rapportert i tidligere studier der søskenflokkdata ikke har vært tilgjengelige. Søskenflokkstudier har også bidradd til å synliggjøre miljøets rolle som årsak til medfødte misdannelser; som ventet er gjentakelsesrisikoen for medfødte misdannelser lavere når mor har byttet partner, men den er enda mer redusert etter at mor har flyttet til en ny kommune.

Datagrunnlaget for forskningen basert på MFR må ofte suppleres med ytterligere data både med hensyn på eksposisjon og oppfølgning. Dette er bakgrunnen for en landsomfattende kohortstudie der alle gravide i landet i en toårsperiode vil bli anmodet om å delta med å besvare tre spørreskjemaer i løpet av graviditeten og å avgi to blodprøver til en biobank. Kvinnene og deres barn vil senere bli fulgt opp over lengre tid. Dette forskningsprogrammet vil gi muligheter for tallrike perinatalepidemiologiske delstudier samtidig som det vil gi muligheter for å belyse sammenhenger mellom perinatale risikofaktorer og sykdom senere i livet. I dette perspektiv vil MFR etter hvert få relevans i det meste av norsk epidemiologisk forskning.
\end{abstract}

Irgens L. The Medical Birth Registry of Norway, a foundation stone in Norwegian epidemiological research. Nor J Epidemiol 1997; 7 (1): 5-10.

\section{ENGLISH SUMMARY}

The Medical Birth Registry of Norway (MBRN) was established in 1967 in the wake of the thalidomide catastrophe which caused more than 10,000 cases of reduction deformities throughout the world. The specific objective was to detect, as soon as possible, increased rates of birth defects, and in general, to establish a basis for epidemiological research of perinatal health problems. This dual objective, related to management and research, has influenced the functions of MBRN.

An important management function is the epidemiological surveillance of perinatal health problems which has contributed to the clarification of a series of clusters and to reduce the uncertainty attached to birth defects and the environment. So far the greatest challenge has been the surveillance after the Chernobyl accident in 
1986. However, a complex environment, involving a magnitude of serious threats to human health, represents a future challenge. The other management function comprises quality control of health services in pregnancy, birth and infancy.

The epidemiological research addresses causes of perinatal health problems as well as follow up of various perinatal conditions such as low Apgar score and the different non-lethal birth defects with respect to survival and function.

Through the years, longitudinal research has been given high priority, defining the sibship rather than the single birth as the unit of analysis. In this research, the clinical high risk group «grand multi-parity» has turned out to be a misnomer. The high risk, observed in cross sectional studies, is caused by heterogeneity due to the fact that many high parity mothers have lost previous infants and thus carry a high risk. Multiparous mothers with no previous loss carry a very low risk. Sibship studies of sudden infant death syndrome have established a much lower recurrence risk than those observed in previous studies by other groups who were unable, due to lack of data, to employ the sibship method. By using the sibship method, evidence is obtained that environmental factors play an important role in the etiology of birth defects; as expected the recurrence rate is reduced if the mother has a new partner, but even more so if the same couple moves to another municipality.

MBRN based research must often be supplemented with further data on both exposure and follow up. For this reason, a national cohort study is under planning in which all pregnant women will be asked to participate by answering three questionnaires and by giving two blood specimens for a biological bank. The women and their children will be followed up over a long period of time. This research programme will enable the focusing of a series of perinatal problems as well as the potential associations between perinatal risk factors and disease later in life. In this perspective, MBRN will eventually have a central role in the majority of epidemiological research in Norway.

Viktige datakilder i norsk epidemiologi er Statistisk sentralbyrå med Dødsårsaksregisteret, Kreftregisteret, Statens helseundersøkelser med blant annet Conorstudiene, hjertekarundersøkelsenene i Tromsø og Medisinsk fødselsregister.

Ved den sjette norske epidemiologikonferansen i 1996 var det akseptert tilsammen 37 foredrag. Av disse var 11 basert på materiale fra MFR. Dette var fullt på høyde med de andre datakildene. For 1995 med 46 arbeider var forholdet mellom datakildene tilnærmet det samme. Disse tallene er nødvendigvis ikke fullt ut representative for norsk epidemiologisk forskning de senere år, men vitner likevel om at MFR synes å ha lykkes med å få bred anvendelse for sine data i norsk epidemiologisk forskning.

\section{BAKGRUNN OG FORMÅL}

I kjølvannet av thalidomidekatastrofen tidlig på 1960tallet ble det i mange land opprettet overvåkingssystemer for tidlig å påvise hyppighetsøkninger av medfødte misdannelser. Mer enn 10.000 barn ble født med alvorlige ekstremitetsmisdannelser, og man ville prøve å unngå slike omfattende konsekvenser av nye teratogener $\mathrm{i}$ fremtiden. De tre første ble etablert $\mathrm{i}$ 1967 i Syd-Amerika, Atlanta og i Norge. Disse tre, sammen med nærmere 30 andre tilsvarende organisasjoner i alle 5 verdensdeler, har de siste ca 20 år samarbeidet innenfor International Clearinghouse for Birth Defects Monitoring Systems (1).

Allerede fra første stund drev MFR en todelt virksomhet: epidemiologisk forvaltning og epidemiolo- gisk forskning. Dette er senere nedfelt i MFRs statutter som ble fastsatt av Helsedirektøren i 1984 (2).

I henhold til statuttene omfatter forvaltningsoppgavene epidemiologisk overvåking av

- medfødte misdannelser og andre perinatale helseproblemer og av

- helsetjenestetilbud i forbindelse med svangerskapsomsorg, fødselshjelp og perinatal omsorg; den siste funksjonen ville i dagens språk blitt beskrevet som tilsyn og kvalitetssikring.

Forskningsoppgavene knytter seg til «årsaksforhold av betydning for sykdom og funksjonshemning hos nyfødte og spedbarn». Feltet er i praksis todelt: dels å avklare årsaker til medfødte misdannelser og andre perinatale helseproblemer, dels å belyse, i oppfølgningsstudier, konsekvensene av perinatale risikofaktorer for senere helse og funksjonshemning.

MFR bygger på et meldeskjema som ble tatt $\mathrm{i}$ bruk 1/1-67. Med hjemmel i jordmorloven (1898) og legeloven (1927) ble det gjennom rundskriv fra Helsedirektoratet bestemt at jordmødre/leger skulle fylle ut dette skjema ved enhver fødsel fra og med 16. svangerskapsuke (2). Daværende overlege i Helsedirektoratet, Fredrik Mellbye, beskrev allerede i 1967 de formål som senere er nedfelt i statuttene (3). Han avsluttet slik: «Staten må her legge til rette for en vitenskapelig aktivitet med en bestemt målsetting som direkte kan komme det praktiske helsearbeid til hjelp. Den tid er forbi da vi på en rekke av de medisinske områder hvor samfunnet har påtatt seg et betydelig ansvar, kan basere oss på et skjønn alene». 


\section{ORGANISASJON}

Senere erfaring har vist at staten kan «legge forholdene til rette» etter to ulike modeller, som faktisk begge har vært benyttet for MFR.

Den opprinnelige plan var at opplysningene som ble samlet inn, skulle bearbeides og analyseres av Statistisk sentralbyrå på samme måte som for opplysningene gitt i legeerklæringen om dødsfall. Slik ble også de første skjemaårgangene innsamlet og bearbeidet.

Statistisk sentralbyrå fant imidlertid at etablering og drift av et overvåkingssystem som løpende skulle vurdere forekomsten av medfødte misdannelser, lå utenfor dets virksomhetsområde. Det ble derfor i desember 1969 inngått en avtale mellom Helsedirektoratet og Statistisk sentralbyrå om å stille materialet til disposisjon for professor dr.med. Tor Bjerkedal, Institutt for hygiene og sosialmedisin, Universitetet $\mathrm{i}$ Bergen for videre bearbeidelse. Dette betydde i realiteten opprettelsen av MFR som egen registerorganisasjon. MFR har senere vært knyttet til Universitetet i Bergen. Bjerkedal ledet arbeidet til sin avskjed i 1976 og senere i samarbeid med instituttledelsen frem til 1984 da det ble inngått en driftsavtale mellom Statens institutt for folkehelse og Universitetet i Bergen. På dette tidspunkt hadde Helsedirektøren som registereier gitt registeransvaret til Statens institutt for folkehelse. Senere har MFR med grunnlag i denne avtalen vært drevet ved Universitetet i Bergen.

I motsetning til andre land har Norge mange epidemiologiske registerinstitusjoner med en relativt fri tilknytning til sentrale statlige organer. Denne organisasjonsformen tar vare på identitet og profil. Samtidig som den innebærer nær kontakt med helsemyndighetene og Statistisk sentralbyrå muliggjør den også tilknytning til faglige forskningsmiljøer. Sannsynligvis lengst $i$ denne retning har MFR gått med sin tilknytning til Universitetet i Bergen. Mye tyder på at denne organisasjonsformen har vært gunstig når det gjelder bruken av MFRs data $i$ forvaltning og forskning. De andre nordiske land har valgt en mer byråkratisk modell med integrering av fødselsregistrene sine i Socialstyrelsen/ Sundhedsstyrelsen. Finland har valgt en mellomting ved å knytte sitt register, som ble etablert så sent som for et par år siden, til STAKES (Forsknings- och utvecklingscentralen för social och hälsovården). Mye tyder på at MFR er det av de nordiske registre som har hatt den beste tilgjengeligheten for andre brukere innenfor og utenfor helsevesenet og dermed fătt den største anvendelsen i forskning og utredning såvel som i forvaltningen.

\section{VIRKSOMHET}

Virksomheten ved MFR frem til idag har, i samsvar med statuttene, vært todelt, dels rettet mot forvaltning dels mot forskning.

\section{Epidemiologisk forvaltning}

Med thalidomidekatastrofen i 1960-årene som bakgrunn ble MFR allerede fra begynnelsen av rettet mot epidemiologisk overvåking av medfødte misdannelser og andre helseproblemer, det vil si klare forvaltningsoppgaver. Allerede tidlig på 1970-tallet var overvåkingssystemet etablert, et system som først ble erstattet med ny metodologi for et par år siden basert på Rolv Terje Lies doktorarbeid fra 1992 (3). Dette opprinnelige systemet kom til å avdekke flere reelle hyppighetsøkninger. Således viste det alarm for gastroschise samtidig med at forekomsten økte i andre land på 1970-tallet. Årsaken er aldri blitt klarlagt. Eksempelet gastroschise illustrerer for øvrig problemene knyttet til hvilke nosologiske/etiologiske enheter man skal overvåke. ICD hadde på dette tidspunktet ingen egen kode for gastroschise, og analysen måtte bygge på en rekoding av alle bukveggsdefektene.

Blant tallrike falske alarmer gjennom årene var en epidemi av hofteleddsdysplasier av de mer kuriøse. Denne skyldtes endrede kriterier for tilstanden, lansert $i$ et kurs for neonatologer like før. Clustre hører epidemiologisk overvåking til. MFRs første alvorlige prøve ble Bømlo. Bømlo ble bekreftet som et signifikant cluster av perinatale dødsfall, men årsaken forble uviss. Episoden medførte en rapport til fylkeslegen i Rogaland (1981). Senere har MFR blitt stilt overfor en rekke mistenkte clustre med betydelig uro i befolkningen og ikke minst i massemediene. Det overveiende flertall har vist seg ikke å være statistisk signifikante clustre. For tiden er MFR engasjert av Sjøforsvaret for å avklare et cluster av ekstremitetsmisdannelser som mistenkes fremkalt av sterke radiosendere ombord i enkelte av Marinens fartøyer.

Eksemplene har det til felles at hyppighetsøkningene kan skyldes ulike aspekter ved miljøet i betydningen: all ikke-genetisk eksposisjon. For 10 år siden, i mai 1986, stod MFR overfor en av sine alvorligste oppgaver i form av en dramatisk miljøforurensing. Tsjernobylulykken førte til radioaktivt nedfall med potensielt meget uheldige konsekvenser for den perinatale helsen i Norge. Samarbeid med Statens strålevern stilte til disposisjon kommune- og månedsspesifikke målinger av ekstern og matvarebasert radioaktiv stråling i til sammen 36 måneder etter ulykken. Denne eksposisjonsdatabasen ble sammenholdt med forekomst av medfødte misdannelser og andre perinatale helseproblemer, slik at det ble mulig å vurdere dose- responssammenhenger. Analysene viste en betydelig nedsatt fertilitet i Norge året etter ulykken, ingen økning i selvvalgte aborter samt en statistisk signifikant økning i spontanaborter. Det ble ikke påvist økt hyppighet av medfødte misdannelser. Samarbeidet med Statens strålevern gjorde det mulig for MFR å foreta en grundigere analyse av Tsjernobylulykkens perinatalmedisinske konsekvenser enn $\mathrm{i}$ de fleste andre land $(4,5)$. 


\section{Epidemiologisk grunnforskning}

Allerede fra begynnelsen av 1970-årene stod epidemiologisk grunnforskning på MFRs program. De to første årgangene dannet grunnlag for en serie arbeider om perinatale helseproblemer hos barn av mødre med spesielle sykdommer som astma (6), nevroser (7), epilepsi (8) og tuberkulose (9). Senere føyet diabetes seg inn i denne serien $(10,11)$.

Alle disse studiene bygget på MFR som eneste datakilde. En ny strategi ble innført da Bjerkedal koblet MFR mot Folke- og boligtellingen av 1970 med henblikk på å studere perinatale helseproblemer $\mathrm{i}$ ulike yrkesgrupper (12). Slik kobling ble meget forutseende hjemlet i MFRs konsesjon fra 1984, der det åpnes adgang til samkjøring med Sentralregisteret for folkeregistrering, Dødsårsaksregisteret, Folke- og boligtellingsregisteret samt helsevesenets epidemiologiske registre.

Kobling mot dødsårsaksregisteret og samarbeidet med Statistisk sentralbyrå som innebærer at MFR får tilsendt kopi av alle dødsmeldinger for spedbarnsperioden, la grunnlaget for MFRs krybbedødsforskning. Nitid revisjon av dødsmeldingene for samtlige mulige krybbedødsfall, et arbeid som startet på begynnelsen av 1980-tallet, viste at vi stod overfor en betydelig hyppighetsøkning fra midten av 1970-årene $(13,14)$. Lenge ble denne trenden betvilt, og særlig av patologer. Nå synes det å være almen tilslutning til MFRs analyse, som innebar en hyppighetsøkning med en relativ risiko på mer enn 3 fra 1970 til 1989, justert for mors alder, paritet og fødselsvekt. Datamaterialet danner nå grunnlaget for et doktorgradsarbeid av Nina Øyen.

Nasjonalt sett fikk denne forskningen stor betydning fordi den åpnet helsevesenets og forskningsrådenes øyne for et nytt helseproblem som krevde ressurser. Den alarmerende tidstrenden for krybbedød var sannsynligvis den viktigste årsaken til etableringen av spedbarnsdød som et eget forskningsprogram. MFR satset her i 1990 ved etableringen av den store nordiske krybbedødsstudien. Den epidemiologiske komponenten, en multisenter pasient kontrollstudie, blir ledet av MFR. Datainnsamlingen pågikk fra 1/9-92 til 31/8-95 og gav opplysninger fra 244 pasienter og 870 kontroller. Resultatene er nå under publisering.

MFR stod også bak en studie som viste at andel spedbarn i mageleie samvarierte med krybbedødsraten både i perioden med økning frem til 1989 og senere når raten nå har falt til 0,5 per 1000 (15). Tilsvarende studier har ennå ikke vært gjennomført $\mathrm{i}$ andre land.

Allerede midt på 1980-tallet fikk krybbedødsforskningen ved MFR internasjonalt gjennomslag ved resultatene av søskenflokkstudier som viste at gjentakelses-overrisikoen ikke var 10, som rapportert av andre, men 3,7, en overrisiko som knapt var signifikant (16). Denne studien er verdt å nevne av to spesielle grunner. For det første representerte den et samarbeid med et amerikanske forskningsmiljø, i dette tilfellet med University of Washington i Seattle v. Donald R. Peterson. Kontaktene med flere amerikanske forskningsmiljøer viser seg å være befruktende og gunstig når det gjelder å nå frem internasjonalt med forskningsresultater. For det andre var denne krybbedødsstudien en av de første søskenflokkstudier fra MFR. Den første studien der søskenflokker ble spesielt omtalt, kom i 1979 (17).

Søskenflokkstudier er senere blitt et kjennemerke ved MFRs forskning og ble særlig sterkt poengtert $i$ Rolv Skjærvens doktorgrad fra 1989: «Dependencies in perinatal outcome between successive siblings» (18). Et gjennomgående funn er at ulike typer uønskede svangerskapsutfall har en tendens til å gjenta seg i påhverandrefølgende svangerskap, noe som kan gi fullstendig feilaktige estimater for paritetseffekter når de vurderes i tverrsnittsstudier.

En søskenflokkstudie som har vekket adskillig oppsikt internasjonalt, var bygget på to spesielle eksposisjonsvariabler som begge ble hentet fra MFR selv (19). Det var en gjentakelses-studie av medfødte misdannelser der de to eksposisjonsvariablene var henholdsvis mors bokommune og partner. Studien viste, ikke uventet, at de barn en mor fikk med en ny partner hadde en lavere gjentakelsesrisiko. Høyst uventet ble det imidlertid funnet at bytte av bokommune reduserte gjentakelsesrisikoen enda mer, noe som antyder betydningen av miljøfaktorer innenfor etiologien for medfødte misdannelser.

MFR benyttes stadig mer også for kliniske problemstillinger, særlig innenfor obstetrikk og pediatri. Således anvender Svein Rasmussen MFR som grunnlag for et doktorarbeide om abruptio placentae $i$ Norge $(20,21)$.

MFR har i økende grad deltatt i internasjonalt forskningssamarbeid, både innenfor International Clearinghouse for Birth Defects Monitoring System, International collaborative Efforts on Perinatal and Infant Mortality og det nordiske fødselsregister samarbeid. Det siste har ført til en serie publikasjoner utgitt av Nordisk Medicinalstatistisk komité (22), samt en nordisk fødselsrecordbasert database med årganger av alle fødte i Norden. Denne databasen ble opprettet på initiativ av MFR og er åpen for alle forskere. MFR har benyttet den som delgrunnlag for et doktorarbeid av Anne Kjersti Daltveit (23).

MFR deltar også i nasjonale forskningsnettverk og har eksempelvis en koordinerende rolle i det samarbeidet om registrering av in vitro fertilisering som fagmiljøene tok initiativet til i 1987 (24). Statens helsetilsyn arbeider nå med å få istand en permanent registrering $\mathrm{i}$ MFR av in vitro fertilisering $\mathrm{i}$ Norge. MFR deltar i omfattende samarbeidsprosjekter med andre institusjoner. Spesielt kan nevnes et doktorarbeid av Petter Kristensen ved Statens arbeidsmiljøinstitutt om reproduksjonsutfall og kreft hos barn av 
bønder. I denne studien er MFR koblet mot jordbrukstellinger og Kreftregisteret (25). Samarbeidet med Statens institutt for folkehelse er særlig omfattende. Et doktorarbeid ved Camilla Stoltenberg om perinatale helseproblemer hos barn av innvandrermødre er kommet istand ved kobling av MFR til Statistisk sentralbyrås registre over fødeland og utdannelse.

Forøvrig leverer MFR data til et stort antall prosjekter uten annet samarbeid enn det som angår selve dataleveransen. Vi har, så langt vi har kunnet, prioritert disse ulike formene for eksternt samarbeid, men dessverre er våre små personellressurser en alvorlig begrensning.

\section{UTFORDRINGER}

Med en stadig synkende perinatal dødelighet og nå også en synkende spedbarnsdødelighet kan det spørres om det gjenstår utfordringer for perinatalmedisinsk forskning generelt og MFR spesielt. Svaret er et ubetinget ja og utfordringene er større enn noen sinne tidligere både innenfor forvaltning og forskning. Forvaltningsmessig vil epidemiologisk overvåking bli stadig viktigere $\mathrm{i}$ årene som kommer. Det fødes fremdeles ca. 1800 barn i Norge per år med medfødte misdannelser, av dødfødsler er det ca. $600 \mathrm{og}$ av spedbarnsdødsfall ca. 500 per år. For langt de fleste av disse perinatale og postperinatale helseproblemene er årsakene ukjente, men vi har sterke holdepunkter for at miljøfaktorer kan ha stor betydning. Vi omgir oss med et stadig mer komplekst miljø der de helsemessige implikasjoner ikke alltid er klarlagt. Stadig oftere konfronteres vi i massemedia med mulige miljøtrusler som kan skape usikkerhet og frykt. En viktig utfordring i fremtiden vil være å ha en epidemiologisk beredskap i form av datagrunnlag og kompetanse til å avklare slike miljøtrusler.

Perinatal diagnostikk og fosterindisert abort representerer en annen utfordring for MFR. Helsedepartementet har tatt initiativ til en registrering i MFR av denne virksomheten, dels for å bedre datagrunnlaget for overvåkingen av medfødte misdannelser, dels for å få en løpende oversikt over omfanget av de fosterindiserte abortene.

Forskningsmessig må vi ta utgangspunkt $i$ at misdannelser og fødselskomplikasjoner er en av de viktigste årsakene til langvarig funksjonshemning og tap av leveår. Forebyggelse av dødsfall og funksjonshemning er ikke mulig uten etiologisk kunnskap. Fallet i krybbedødsraten ble oppnådd gjennom epidemiologisk forskning og forskningsbaserte forebyggende tiltak. For forebyggelsen av medfødte misdannelser er det mulig at folsyre kan få en like avgjørende betydning som endret sovestilling fikk for krybbedød (26), men her gjenstår ennå en rekke ubesvarte spørsmål. I årene som kommer fremstår interaksjon mellom genetisk disposisjon og miljøagens som en interessant etiologisk modell for perinatalepidemiologisk forskning. MFR er allerede engasjert i slik forskning gjennom en studie av leppeganespalte ledet av Rolv Terje Lie.

Med et longitudinelt perspektiv på epidemiologien har tanken om perinatale årsaksfaktorer til hjertekarsykdommer og kreft fått gjennomslag. Allerede i 1977 fant Forsdahl holdepunkter for en sammenheng mellom dårlige leveforhold i barndommen og høy risiko for arteriosklerotisk hjertesykdom (27). Barker og medarbeidere har påvist tilsvarende sammenhenger i longitudinelle studier (28). Om ikke mange år vil MFR gi grunnlag for omfattende undersøkelser av slike mulige sammenhenger, og data fra MFR vil etter hvert kunne bli relevante $\mathrm{i}$ det meste av norsk epidemiologisk forskning.

MFR var i utgangspunktet et utpreget utfallsregister. Selv om det nå er tatt initiativ til å få registrert mors røkevaner og yrke $i$ et nytt registreringsskjema for MFR, inneholder registeret relativt få opplysninger om eksposisjon. Dette er noe av bakgrunnen for planleggingen av et stort forskningsprogram, «Bedre helse for mor og barn» der samtlige gravide i landet gjennom en toårsperiode vil bli anmodet om å delta. Deltakerne vil bli bedt om å besvare tre spørreskjemaer (hvorav ett om kosthold) og avgi to blodprøver i løpet av svangerskapet. Disse opplysninger om eksposisjon vil bli sammenholdt med utfall registrert i MFR og andre utfallsregistre. Dette forskningsprogrammet, som er åpent for deltakelse fra alle norske epidemiologiske miljøer, vil bli en rik kilde til epidemiologisk forskning i Norge i årene som kommer.

Under alle disse arbeidsoppgavene ligger den grunnholdning at forebyggelse generelt har de største muligheter til å lykkes når tiltakene iverksettes så tidlig som mulig, det vil si når det nye liv oppstår. Dette vil alltid være en spesiell utfordring for MFR.

\section{REFERANSER}

1. Annual report 1993, International Clearinghouse for Birth Defects Monitoring Systems.

2. Årsmelding 1985 for Medisinsk fødselsregister, Universitetet i Bergen i samarbeid med epidemiologisk enhet, Statens institutt for folkehelse.

3. Lie RT. Detecting Changes in Perinatal Risks. Epidemiological studies based on the Medical Birth Registry of Norway, with implications for the methodology of surveillance of birth defects and other conditions in the newborn, University of Bergen 1992. 
4. Irgens LM, Lie RT, Ulstein M, Skeie Jensen T, Skjærven R, Sivertsen E, Reitan JB, Strand P, Strand T, Skjeldestad FE. Pregnancy outcome in Norway after Chernobyl. Biomed Pharmacother 1991; 45: 233-241.

5. Lie RT, Irgens LM, Skjærven R, Reitan JB, Strand P, Strand T. Birth defects in Norway by levels of external and food-based exposure to radiation from Chernobyl. Am J Epidemiol 1992; 136: 377-88.

6. Bahna SL, Bjerkedal R. The course and outcome of pregnancy in women with bronchial asthma. Acta Allergol 1972; 27: 397-406.

7. Bahna SL, Bjerkedal T. The course and outcome of pregnancy in women with neuroses. Acta Obstet Gynecol Scand 1974; 53: 129-133.

8. Bjerkedal T, Bahna SL. The course and outcome of pregnancy in women with epilepsy. Acta Obstet Gynecol Scand 1973; 52: 245-248.

9. Bjerkedal T, Bahna SL, Lehmann EH. The course and outcome of pregnancy in women with pulmonary tuberculosis. Scand J Resp Dis 1975; 56: 245-250.

10. Jervell J, Moe N, Bjerkedal T. Diabetes mellitus og svangerskap. Tidsskr Nor Lageforen 1979; 99: 784-786.

11. Jervell J, Bjerkedal T, Moe N. Outcome for pregnancies in diabetic mothers in Norway 1967-1976. Diabetologia 1980; 18: 131-134.

12. Bjerkedal T. Occupation and outcome of pregnancy: A population-based study in Norway. In Prevention of Physical and Mental Congenital Defects, Part B: Epidemiology, Early Detection and Therapy, and Environmental Factors. Alan R. Liss, New York, 1985: 265-268.

13. Irgens LM, Skjærven R, Lie RT. Secular trends of sudden infant death syndrome and other causes of post perinatal mortality in Norwegian birth cohorts. Acta Paediatr Scand 1989; 78: 228-232.

14. Øyen N, Irgens LM, Skjærven R, Morild I, Markestad T, Rognum TO. Secular trends of sudden infant death syndrome in Norway, 1967-1988. Application of a method of case identification to Norwegian registry data. Paediatr Perinat Epidemiol 1994; 8: 263-281.

15. Irgens LM, Markestad T, Baste V, Schreuder P, Skjærven R, Øyen N. Sleeping position and SIDS in Norway 1967-1991. Arch Dis Child 1995; 72: 478-482.

16. Irgens LM, Skjærven R, Peterson DR. Prospective assessment of recurrence risk in sudden infant death syndrome siblings. J Pediatr 1984; 104: 349-351.

17. Bakketeig LS, Hoffman HJ. Perinatal mortality by birth order within cohorts based on sibships. $B r \mathrm{Med} J$ 1979; 2: 693-696.

18. Skjærven R. Dependencies in perinatal outcome between successive siblings. Influences on traditional measures in perinatal epidemiology assessed on the basis of births in Norway, 1967-1984. University of Bergen, 1989.

19. Lie RT, Wilcox AJ, Skjærven R. A population-based study of the risk of recurrence of birth defects. $N$ Engl J Med 1994; 331 (1): 1-4.

20. Rasmussen S, Irgens LM, Bergsjø P, Dalaker K. The occurrence of placental abruption in Norway 1967-1991. Acta Obstet Gynecol Scand 1996; 75: 222-228.

21. Rasmussen S, Irgens LM, Bergsjø P, Dalaker K. Perinatal mortality and case fatality after placental abruption in Norway 1967-1991. Acta Obstet Gynecol Scand 1996; 75: 229-234.

22. Nordisk Medicinalstatistisk Komite. Births and Infant Mortality in the Nordic Countries 39: 1993.

23. Espehaug B, Daltveit AK, Vollset SE, Øyen N, Ericson A, Irgens LM. Infant survival in Norway and Sweden 1985-88. Acta Paediatr 1994; 83: 977-82.

24. von Düring V, Maltau JM, Forsdahl F, Åbyholm T, Kolvik R, Ertzeid G, Steier A, Baste V, Irgens LM. Svangerskap, fødsel og barn etter in vitro fertilisering i Norge 1988-1991. Tidsskr Nor Lageforen 1995; 115: 2054-2060.

25. Kristensen P, Andersen A, Irgens KM, Bye AS, Sundheim LS. Cancer in offspring of parents engaged in agricultural activities in Norway: Incidence and risk factors in the farm environment. Int J Cancer 1996; 65: 39-50.

26. Vollset SE, Irgens LM. Folinsyre og svangerskap - sikker kunnskap, usikker praksis. Tidsskr Nor Lageforen 1996; 116: 217-8.

27. Forsdahl A. Are poor living conditions in childhood and adolesence an important risk factor for arteriosclerotic heart disease? Br J Prev Soc Med 1977; 31: 91-5.

28. Barker DJP, Winter PD, Osmond C, Margetts B, Simmonds SJ. Weight in infancy and death from ischaemic heart disease. Lancet 1989; ii: 577-80. 